\title{
La Diversificación de los Mercados como Estrategia de la Agricultura Familiar
}

\author{
Clara Craviotti ${ }^{1}$ y Paula Palacios $^{2}$
}

Resumen: Partiendo de distintos abordajes teóricos sobre los mercados, el artículo analiza las formas de comercialización de los fruticultores familiares del noreste de la provincia de Buenos Aires (Argentina). El área reviste particular interés por conformar un sistema productivo local que experimenta desde hace varios años un proceso de retracción, en contraposición a la expansión del cultivo de la soja orientada a los mercados mundiales. El análisis considera el contenido de los vínculos establecidos y la composición de los capitales como condicionantes de la inserción en los mercados, y visualiza a éstos como ámbitos de interacción social donde se construyen nuevas relaciones. Argumenta que en los productores familiares la diversificación de canales comerciales refuerza a la encontrada en el plano productivo, y que los circuitos dominados por grandes empresas y los mercados locales no constituyen alternativas mutuamente excluyentes para este tipo de productores sino complementarias.

Palabras-claves: Agricultura familiar; canales de comercialización; diversificación, fruticultura.

\begin{abstract}
Based on different theoretical approaches on markets, the article analyzes the marketing mechanisms deployed by family fruit growers in the northeast of the province of Buenos Aires (Argentina). The area is of particular interest as a local production system which has been experiencing a retraction process, in sharp contrast with the expansion of soybeans oriented to the world markets. The analysis considers the nature of the links established and the composition of capitals as determinants of market insertion, and regards markets as areas of social interaction where new relationships are built. It argues that the diversification of sale channels reinforces the diversification found in the productive level, and that the circuits dominated by large companies and local markets are used in a complementary way by family farmers, instead of being mutually exclusive alternatives.
\end{abstract}

Key-words: Family farming; marketing channels; diversification; fruit production.

Classificação JEL: Q13, R11, Z13.

1. Investigadora del Consejo Nacional de Investigaciones Científicas y Técnicas (Conicet) en la Facultad de Ciencias Económicas, Universidad de Buenos Aires, Argentina. Profesora de la Facultad Latinoamericana de Ciencias Sociales (FLACSO-Argentina).E-mail: c.craviotti@yahoo.com

2. Docente investigadora del Centro de Investigaciones Geográficas/ Instituto de Investigaciones en Humanidades y Ciencias Sociales- Universidad Nacional de La Plata- Consejo Nacional de Investigaciones Científicas y Técnicas (CIG-IdIHCS-UNLP-Conicet). Facultad de Humanidades y Ciencias de la Educación (FaHCE), La Plata, Argentina. E-mail: palacios.ep24@gmail.com 


\section{Introducción}

En Argentina, la expansión de un sistema agroalimentario apoyado en el cultivo de la soja orientada a los mercados mundiales ha generado significativos cambios en las áreas rurales incluyendo a la propia región pampeana, epicentro del desarrollo agrario argentino. En tanto esta expansión no se produjo en un espacio vacío, un interrogante central refiere a sus implicancias sobre las formas de organización del territorio y las interrelaciones rural-urbanas, así como sobre los sujetos sociales agrarios allí presentes. Ello implica preguntarse por la importancia que tienen los fenómenos de exclusión y las posibles reconfiguraciones de aquellos que han logrado persistir, ya sea desde el punto de vista de sus recursos y posición en la estructura social agraria, como en cuanto a las prácticas que despliegan, sus vínculos con otros agentes, y sus comportamientos colectivos como actores sociales.

El noreste de la provincia de Buenos Aires con eje en el partido de San Pedro reviste particular interés desde esta perspectiva puesto que en dicha área se han desarrollado producciones trabajo-intensivas como la fruticultura, con rasgos propios de un cluster o sistema productivo local. No obstante la actividad sufre desde hace varios años un proceso de retracción que contrasta con la expansión de la agricultura extensiva: Así mientras la soja abarca hoy unas 250.000 hectáreas, la superficie dedicada a los frutales (cítricos y duraznos fundamentalmente) ocupa sólo 6.700 (habiendo llegado a un pico de 16.600 en 1993). En ese contexto la cantidad de explotaciones frutícolas ha disminuido en un 58 \% en el período 2002-2008, siendo la caída más pronunciada en las más pequeñas (PAGLIARICCI, 2011). Actualmente existiría no más del $15 \%$ del número de unidades relevado en 1980, lo que da cuenta de la magnitud del proceso de exclusión de productores asociado a la retracción de la fruticultura local. ${ }^{3}$

Al mismo tiempo estos datos sugieren la redefinición del territorio del noreste de la provincia de Buenos Aires como productorabastecedor de frutas frescas, mientras otras áreas del país logran consolidarse en esa función. ${ }^{4}$ Los factores que inciden en este proceso son variados y operan en diferentes escalas. Algunos de ellos se vinculan con la propia

3. Por otra parte este hecho tiene indudables repercusiones sobre el mercado de trabajo, en tanto la demanda de mano de obra ha sido estimada por el Instituto Nacional de Tecnología Agropecuaria (INTA) en 80 jornales/ha/año en frutales de carozo y 60 en cítricos, mientras que en sólo 0,5 jornales/ha/año en el caso de la soja.

4. En duraznos Mendoza es actualmente la principal provincia productora de Argentina, aunque la mayoría de su producción corresponde a la variedad destinada a conservas. En el caso de las naranjas, Entre Ríos aporta poco más del 50\% del total producido (Federcitrus, 2010). 
fruticultura (afectada por una política económica desfavorable para la actividad, y en relación al área que se viene analizando, por contingencias climáticas), mientras que otros tienen que ver con las características de cultivos de tipo plurianual, intensivos en mano de obra, en relación a cultivos de ciclo corto, como es el caso de la soja, que además se basa en un paquete tecnológico simplificado, que demanda escasa mano de obra.

Frente a este panorama adverso, Craviotti y Palacios (2013) analizaron algunas de las estrategias de persistencia desplegadas por los fruticultores familiares -definidos como tales en función de su involucramiento en tareas físicas y de gestión- apuntando a su comprensión desde sus propios marcos de significado. Identificaron por un lado una fuerte tendencia al incremento de la diversificación productiva, orientada a disminuir los riesgos climáticos y de mercado, bajar la incidencia de costos fijos y atenuar la estacionalidad de los ingresos, objetivo al que también apunta el desarrollo de actividades paraagropecuarias y extraprediales (pluriactividad). Otras prácticas en el plano productivo, consistentes en la intensificación del trabajo familiar, el ahorro de gastos monetarios (particularmente en materia de insumos comprados) y la obtención de recursos mediante circuitos no mercantiles presentan componentes resistenciales y se distancian del modelo productivo hegemónico. En el plano opuesto pueden ubicarse otros comportamientos (como la certificación de lotes citrícolas para exportación, la realización de un plan sostenido de pulverizaciones y la recurrencia al asesoramiento técnico privado), si bien son minoritarias en este tipo de productores.

Los agricultores familiares manejan explotaciones por debajo de las 200 hectáreas, aunque la mayoría trabaja 50 y posee no más de 20 implantadas con frutales, a las que principalmente accedieron por herencia. El productor familiar "puro" trata de estructurar su esquema productivo en torno a la mano de obra familiar y maximizarla para no contratar jornales. La distribución de tareas se complejiza cuando la unidad de producción responde al perfil de un productor familiar-empresarial, en este caso la familia participa fuertemente de las tareas, aunque también contrata algún trabajador permanente.

Las estrategias desplegadas en el plano predial son no obstante indisociables de las adoptadas en la esfera de la comercialización. Por ello en este artículo procuramos entender la participación en los mercados de los fruticultores familiares del área, partiendo de la hipótesis general de que la coordinación horizontal, así como la articulación con otros actores públicos y privados en el nivel local contribuyen a su persistencia, en un contexto problemático signado por la expansión de un modelo productivo basado en economías de escala.

En relación a la estrategia metodológica empleada, nos basamos en el análisis de entrevistas en profundidad a 19 productores familiares, que representan el $20 \%$ del total de productores del área, así como a empresas verticalmente integradas (con empaques de clasificación y procesamiento de fruta ubicados en el partido de San Pedro), y entrevistas a otros informantes calificados locales (técnicos, proveedores de insumos, referentes de organizaciones públicas y privadas). ${ }^{5}$ Estas fuentes fueron complementadas con la consideración de la información estadística disponible, que brinda un panorama sobre el marco más general en que se desenvuelven estos productores.

El artículo se organiza en cuatro secciones. En el apartado que sigue se presentan algunos fundamentos generales sobre la participación en los mercados de los productores familiares a partir de la revisión de trabajos previos sobre la temática. Posteriormente se analizan los canales comerciales empleados por los fruticultores del área, los agentes con los cuales interactúan y el carácter de los vínculos establecidos, para luego abordar sus estrategias de participación en los distintos mercados y las conclusiones finales.

5. La investigación se enmarca en el proyecto PICT 1025, financiado por la Agencia Nacional de Promoción Científica y Tecnológica de Argentina. La información de campo en que se basa este artículo fue generada en 2011, durante cinco estadías efectuadas en distintos momentos del ciclo productivo de la fruta. 


\section{Los productores familiares y la comercialización de su producción: aportes teóricos}

Los cambios en los sistemas agroalimentarios, principalmente identificados a partir de la fase de globalización y desregulación de los mercados, han modificado el escenario donde tradicionalmente se desenvolvían los productores en pequeña escala, al implicar la consolidación e internacionalización de la gran distribución -súper e hipermercados-, el desarrollo de estándares privados de calidad -que complementan a los marcos regulatorios de carácter público-y las modalidades de coordinación vertical y abastecimiento centralizado.

Reconociendo estas tendencias, los estudios han recorrido dos vertientes analíticas $y$ propositivas, que en la práctica han evidenciado escasos puntos de contacto entre sí. La primera de ellas se centra en los riesgos de marginación/ exclusión de los pequeños productores, en función de sus dificultades para alcanzar cantidad y una oferta constante del producto, así como por los mayores costos de transacción involucrados (MARKELOVA etal., 2009; HAZELL etal.,2010). En ese contexto, algunos trabajos procuran identificar las condiciones que permitirían su articulación "exitosa" con los canales masivos de venta minorista; por ejemplo, contar con determinadas tecnologías o instalaciones poscosecha, acceder a apoyos institucionales, optar por la venta de su producción en forma asociada, o bien participar en nichos de mercado específicos (BIÉNABE y VERMEULEN, 2008). Más recientemente algunos estudios se concentran sobre los efectos de la implementación de estándares internacionales de buenas prácticas agrícolas sobre este tipo de productores, identificando distintas posibilidades: adaptación, vuelco a mercados o canales alternativos o con menores exigencias (LEE et al., 2009).

Esta corriente también alude a que los mercados internos de los países que experimentaron políticas de desregulación y apertura tienen cada vez más puntos en común con los mercados de exportación, donde las cadenas son controladas por los compradores y se caracterizan por elevados niveles de coordinación vertical (BOSELIE y VAN DER KOP, 2005). En lo que refiere a los productos frutihortícolas, las estrategias de la gran distribución han provocado fuertes reestructuraciones tanto en la producción como en la comercialización, que se traducen en el debilitamiento de los mercados mayoristas, el surgimiento de agentes especializados en la intermediación con la gran distribución, y el aumento de la escala productiva, por su impulso hacia la adopción de tecnologías "modernas" (producción bajo cubierta, riego, variedades de mayor duración, entre otras) (GUTMAN, 2005).

Partiendo de estas tendencias de cambio de los sistemas agroalimentarios, la segunda de las vertientes analíticas analiza a los mercados locales (el caso de las ferias, la venta directa en la propia explotación, entre otras) como alternativa a los circuitos mercantiles dominados por las grandes empresas. Antes considerados como una fuente complementaria de ingresos, algunos de ellos han devenido en el principal canal de ventas para productores en pequeña escala (GRIFFIN y FRONGILLO, 2002). Este tipo de mercados detentarían múltiples ventajas: además de generar una mejora en los ingresos prediales, reconfiguran los valores asociados a los alimentos y posibilitan el desarrollo de conexiones entre productores y consumidores que contrastan con el carácter impersonal de las cadenas globales de aprovisionamiento alimentario, y son especialmente relevantes a partir de las preocupaciones crecientes por la salud y el medio ambiente (MARSDEN et al., 2000). Además, al significar una ruptura con el sistema hegemónico de provisión de alimentos de carácter productivista, industrial y estandarizado, estos mercados locales han sido inclusive visualizados por algunos autores como parte de un nuevo "modelo" de desarrollo rural (RENTING et al., 2003).

La bibliografía sobre mercados locales enfatiza que si bien el incrustamiento social (social embededdness) es esencial para la vida económica en general, sustenta especialmente a estas formas 
de comercialización, en las que están presentes principios de reciprocidad y confianza así como ciertos valores -el "compromiso" con la localidad y con formas de producción "sanas", entre otros - (SAGE, 2003). No obstante, el planteamiento de una clara separación entre los circuitos largosconvencionales y los circuitos cortos-alternativos no resultaría del todo satisfactoria, en tanto no capta la realidad de las prácticas concretas, con productores que circulan entre uno y otro tipo de circuito, o evidencias de traspasamiento de las pautas propias de uno de ellos al otro.

Desde este punto de vista algunos trabajos proponen realizar análisis que permitan poner de manifiesto cómo ambos circuitos se articulan o conectan (DUBUISON-QUELLIER y LE VELLY, 2008). Una posibilidad en esta dirección es analizar cómo los productores familiares, a pesar de su reducida escala productiva, combinan su inserción en mercados diferentes. Este tipo de productores usualmente opera en distintos canales, y despliega en ellos estrategias diferenciadas para satisfacer sus necesidades, sea las de tipo económico (como el acceso al crédito o a un mejor flujo de fondos, el control de riesgos) o sociales (sostener su inclusión en redes sociales relevantes para ellos) (CONFERENCE ISSUES PAPER 4, 2008).

La perspectiva orientada al actor puede ser iluminadora al respecto, en tanto visualiza a los sujetos como capaces de procesar su experiencia social y poner en juego distintas estrategias, si bien reconoce que las elecciones individuales se inscriben en estructuras mayores de significado y acción (LONG y PLOEG, 1994) Aplicado al tema que nos ocupa, este enfoque postula que los productores pueden construir una interacción con los mercados e inclusive reorientar el vector de esta interacción en un sentido que favorezca su reproducción social. Así el hecho de que éstos se involucren en la construcción de redes de comercialización alternativas demostraría que los mercados pueden constituir espacios de resistencia y de (re)construcción de autonomía (CONTERATO et al., 2011). Otro aporte importante de este enfoque es que los mercados dejan de ser percibidos como estructuras rígidas y "externas"; por el contrario, pasan a ser vistos como espacios sociales dinámicos, resultantes de las interacciones entre los productores y los demás actores del mundo rural.

Recuperando estos aportes, en este artículo procuramos analizar las formas de venta de los productores familiares en el contexto de retracción de la superficie frutícola del territorio en que se inscriben, analizando sus prácticas desde tales ejes: cómo construyen su participación en los mercados con vistas a lograr su persistencia, y cómo interactúan con otros agentes, algunos de ellos ubicados fuera del territorio. En este marco, el análisis revelará sus posibilidades de redefinir sus condiciones de inserción pero también ciertos límites, que devienen de su acceso a recursos y posición en el espacio social.

\section{Canales, agentes de comercialización y vínculos}

Una diversidad de actores locales y extralocales interviene en la comercialización de la producción frutícola del noreste de la provincia de Buenos Aires. Ello da como resultado un entramado de relaciones con características propias, a causa de los tipos de vínculos que se establecen entre productores y compradores. Se trata de un sistema de comercialización ramificado en múltiples canales, con lógicas diferentes y donde los actores que participan difieren en cuanto a sus niveles de poder para negociar cada transacción.

En Argentina, a diferencia de lo que sucede con las pomáceas (peras y manzanas) de larga tradición exportadora, y más recientemente con el limón, la producción de naranjas y duraznos se comercializa en una baja proporción en el mercado externo. En el caso del cítrico dulce, sólo el $19 \%$ del total de la producción nacional del año 2010 se canalizó hacia ese destino para su venta en fresco (Federcitrus, 2011), mientras que en el durazno lo exportado en fresco en el año 2010 representó un escaso $2 \%$. El noreste bonaerense manifiesta una situación similar puesto que ambas 
Figura 1. Argentina. Evolución de la participación provincial en el total de las exportaciones de naranjas (\%)

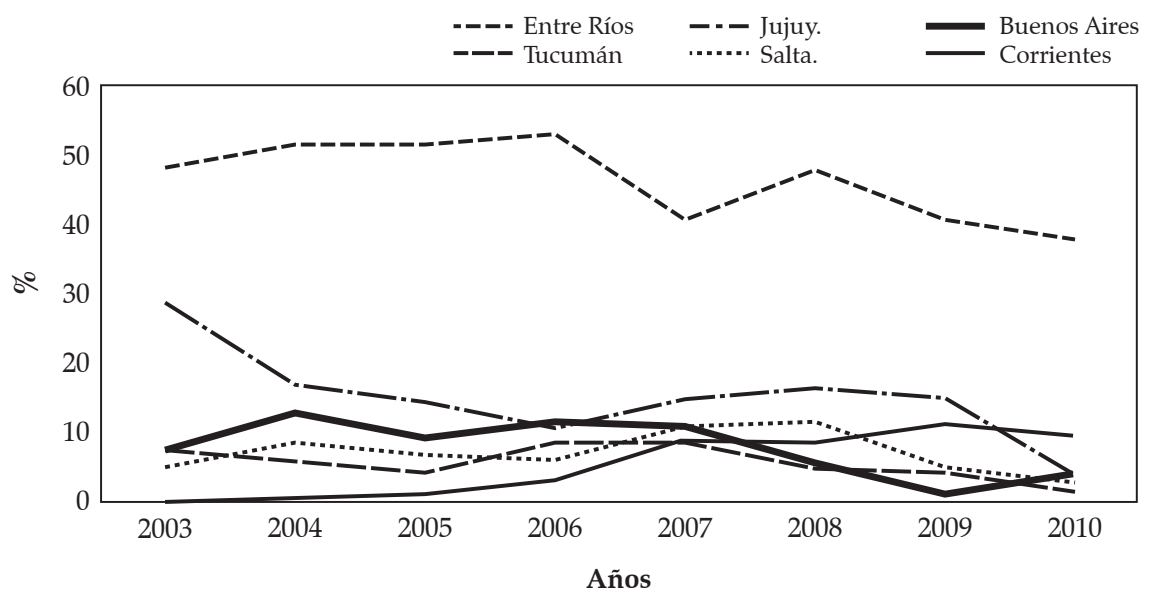

Fuente: Elaboración propia sobre la base de SENASA, varios años.

producciones se destinan fundamentalmente al mercado interno. ${ }^{6}$ Además, y frente al peso que adquieren otras áreas, la contribución de las naranjas de la zona en el total exportado por el país es relativamente baja -alrededor del $10 \%$ en las mejores temporadas- (Figura 1). En función de esta situación es que adquiere relevancia la multiplicidad de circuitos que se emplean para la venta de la fruta en el mercado interno.

\subsection{La venta de la fruta en planta \\ a los galpones de empaque}

Sea con destino al mercado interno como para exportación, buena parte de la producción frutícola del noreste bonaerense es acondicionada en establecimientos empacadores locales que procesan fruta propia y eventualmentela adquirida a otros productores. El sector está integrado por unas seis firmas exportadoras directas, empaques medianos para el mercado interno y la exportación; también participan numerosos galpones pequeños que acondicionan solamente para el mercado doméstico, generalmente a cargo

6. El $80 \%$ de la naranja y el $90 \%$ del durazno local se destinan al mercado interno (estimación en base a datos provenientes del Servicio Nacional de Sanidad y Calidad Agroalimentaria -SENASA- y la Federación Argentina del Citrus -FEDERCITRUS-, 2010 para naranjas y del Instituto Nacional de Tecnología Agropecuaria -INTA- para duraznos). de productores familiares que logran así llegar de manera más directa a los mercados.7 Algunas de las firmas empacadoras locales también procesan fruta para exportación a empresas de capitales extraregionales, como Citrícola San Miguel, Argentinian Fruits o Veracruz. Las que exportan por su cuenta venden a grandes distribuidores internacionales de manera directa o a través de intermediarios. Generalmente las firmas que acondicionan cítricos para exportación tienen fruta de descarte, que colocan en las fábricas de jugos o venden a los empaques de menor escala ubicados en San Pedro y a pequeños distribuidores.

La mayoría de estos establecimientos tratan de acondicionar tanto cítricos como duraznos para prolongar la actividad más allá de la estacionalidad propia de cada especie, de modo de bajar la incidencia de los costos fijos. No obstante es habitual encontrar que aquellos que procesan exclusivamente para el mercado interno tengan capacidad ociosa, ya que trabajan sólo algunos meses del año.

Una característica de la fruticultura local es la integración del eslabón de procesamiento con el de producción, ya sea a través de la propiedad

7. En total y según los registros oficiales están habilitados para operar 58 empaques de fruta de carozo y cítricos; de ellos unos 25 para exportación y el resto para el mercado interno (Servicio Nacional de Sanidad y Calidad Agroalimentaria -SENASA - Cámara de Productores y Empacadores Zona Norte de Buenos Aires- CAPROEM 2008-2011). 
Figura 2. Argentina. Principales áreas de producción de naranjas y duraznos en las provincias de Buenos Aires, Entre Rios y Mendoza

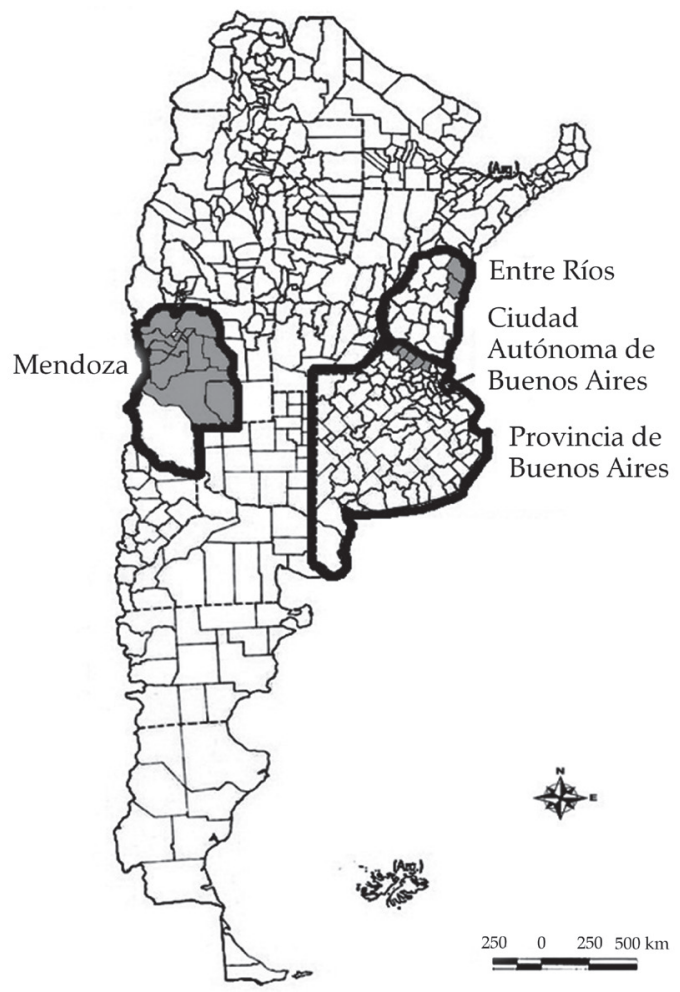

Fuente: Elaboración propia sobre la base de cartografia del INDEC.

o del arriendo de tierras a terceros. ${ }^{8}$ Esta vía permite a estos establecimientos regular o ajustar anualmente la compra de fruta a productores familiares. Según los testimonios esta forma de proceder -que data de unos veinte años atrás- se ha ido acentuando en los últimos tiempos, con consecuencias negativas para los productores que no integran más de un eslabón de la cadena de valor y que ven cómo se reduce el canal de venta a los empaques. Así mientras antiguamente era el empacador el que salía a comprar fruta, inclusive cuando los montes todavía estaban en flor, hoy día el productor inicia la temporada de cosecha con incertidumbre respecto a la venta de la fruta en una producción, como la cítrica muy vulnerable a las heladas.

No sólo el número de productores-empacadores locales que compran fruta a productores no integrados ha ido disminuyendo, sino que

8. En este caso el alquiler se hace mediante contratos escritos por varios años y el pago se pacta a valor quintales de soja. algunos de ellos inclusive prevén dejar de hacerlo en el futuro. Al respecto un empacador de tamaño grande señala: "Yo tenía un productor en Baradero que tenía 110 hectáreas, que tenía 45.000 plantas de fruta, hice un convenio por escrito que durante él tuviera fruta de exportación yo le compraba, le pude comprar durante siete años, el anteaño pasado no sirvió la fruta, no compré, este año no me sirvió la fruta, no compré, y el hombre lo va a arrancar". Su relato deja al descubierto la debilidad del compromiso del empacador hacia el productor, ya que no duda en soltarle la mano cuando la situación deja de ser conveniente. ${ }^{9}$

Inclusive determinadas firmas están evaluando trasladar sus plantas de empaque a la vecina provincia de Entre Ríos (Figura 2) puesto

9. Los empacadores que tomaron la decisión de no comprar más fruta porque alcanzaron la escala óptima de autoabastecimiento manifiestan que en contadas ocasiones suelen trabajar la de algún productor. Cuando lo hacen es porque pesan determinados compromisos ligados a lazos afectivos. 
que los costos les resultan comparativamente menores, aunque tengan que asumir el flete hasta los puertos de embarque ubicados en la provincia de Buenos Aires cuando el destino es la exportación. ${ }^{10} \mathrm{El}$ mismo empacador sostiene "hoy por hoy se está analizando ir a trabajar, poner una máquina allá... [...] la verdad uno se queda acá porque ya te digo, porque es sampedrino, y uno quiere darle todo... se da cuenta que va a dejar acá trabajo indirecto, directo, como sea, mucha gente en San Pedro. [...] Mi mejor negocio sería irme". En casos como éste se trata de empaques de cierta escala y/o que trabajan para exportación de cítricos, que actualmente están comprando fruta a un número más elevado de productores extralocales que locales.

Vale también como dato comparativo el comportamiento de otro de los empacadores del área que acondiciona fruta para grandes firmas exportadoras y compra a 5 productores en San Pedro y a alrededor de 2 fincas grandes en Entre Ríos. Este argumenta que dicha provincia no dispone de la infraestructura suficiente para procesar toda la fruta que produce, y que como el noreste bonaerense tiene muy poca mandarina y sólo variedades tempranas de naranja necesita comprar frutas allí "para sostener también un poco a la gente que tenemos [...] seguir un poco la cadena y poder mantener los clientes que tenemos también en el mercado interno".

Ante esta situación cobran relevancia algunos agentes extralocales que compran fruta en el área y que suelen también contratar el servicio de empaque en la misma. Esto es visualizado en forma positiva por los productores de pequeña escala, en tanto representa una vía alternativa para colocar su producción y les otorga cierto margen de maniobra frente a los productoresempacadores locales que sólo compran fruta a

10.La existencia de este comportamiento es reforzado por trabajos previos, realizados para la zona citrícola del río Uruguay (que abarca los departamentos de Concordia y Chajarí en Entre Ríos, y Monte Caseros en Corrientes), donde se señala el incremento de la venta de cítricos de los productores de Entre Ríos a los empaques habilitados para exportación ubicados en San Pedro y alrededores (Craviotti y Palacios, 2011). terceros en coyunturas de alta demanda o para cubrir mermas de su propia producción.

En las transacciones entre empacadores y productores de tipo familiar no se firma un contrato por escrito, sino que los arreglos se establecen de palabra. Debido a que se han registrado situaciones de incumplimiento el productor prioriza la seriedad y solvencia del comprador. Este en cambio privilegia la calidad del producto, principalmente si es para exportar.

La relación entre las partes muestra signos de mayor estabilidad cuando se trata de productores que preparan su fruta para exportación, pero éstos deben afrontar una serie de gastos para financiar las prácticas diferenciales que demanda el manejo (mayor cantidad de pulverizaciones y con productos más caros) que no están al alcance de la mayoría. De hecho poco más de un tercio de los fruticultores familiares del área apuntan a exportar parte de su producción frutícola. Sin embargo la situación de desequilibrio entre las partes no cambia en este caso:

“Porque...el pequeño productor como nosotros, a vos te llevan la fruta y después vos no sabés que pasa [...]. Yo puedo controlar los bines [cajones] que salen del campo, pero una vez que los empiezan a volcar y te dicen no, de exportación salieron tantas cajas [...] y total qué le vas a decir. No podés controlar, entonces en esto va mucho la seriedad y la confianza que vos le tengas al comprador. Porque además está la otra, yo te compro, bien, llevo la mitad cosechado, cayó una helada ¿qué pasa con lo que quedó? Fuiste..." (caso 4).

El precio suele establecerse unos quince días antes de la cosecha si la venta es en planta, por cajón (la modalidad de venta más común en los productores familiares) o a rendimiento, por caja salida del empaque si los productores se hacen cargo de la cosecha. Sin embargo el precio pactado puede cambiar en el lapso de tiempo que transcurre desde que se negocia hasta el momento de la cobranza, si las condiciones del mercado varían. Oscila también en función de los costos de los empacadores, ya que como 
Figura 3. Provincia de Buenos Aires (Argentina). Evolución de la participación anual de duraznos remitidos al MCBA

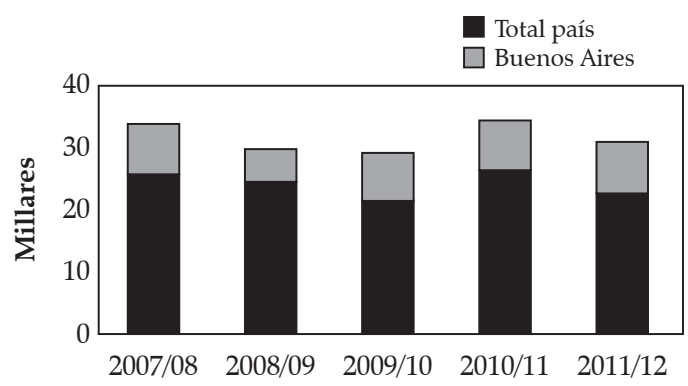

Fuente: Elaboración propia sobre la base de estadísticas del MCBA.

sostiene un empacador grande: "A nosotros como exportadores si el número no te cierra, vos le bajás el precio al productor, todo, todo el fusible mayor de todos los aumentos y todo es para el productor". Este último suele cobrar en un lapso que varía entre 45 a 90 días para el cítrico y 30 a 45 para el durazno (ya que la temporada es más corta y la fruta es de carácter más perecedero).

\subsection{La venta a mercados concentradores}

La fruta ya empacada con destino al mercado interno es en buena medida comercializada a través de mercados concentradores mayoristas. En ellos canalizan su fruta productores de cierto tamaño, que pueden reunir el volumen requerido para justificar los costos de flete y descarga de la fruta, y que les permiten mantener continuidad en el abastecimiento semanal de los puestos de venta. Pueden carecer de empaque propio para acondicionar la fruta y en su lugar contratar dicho servicio, pero esta situación es de por sí poco frecuente.

El Mercado Central de Buenos Aires (MCBA) es el más relevante para la fruticultura del noreste bonaerense, a pesar de que ha ido creciendo la influencia de otros ubicados en el Gran Buenos Aires, como es el caso de Avellaneda, Tres de Febrero y Beccar, a los que se agregan destinos en la provincia de Santa Fe. ${ }^{11}$ De éstos se abastecen

11.La anulación del "perímetro de protección" del MCBA a través del decreto desregulador 2284/91 disminuyó la
Figura 4. Provincia de Buenos Aires (Argentina). Evolución de la participación anual de naranjas remitidos al MCBA

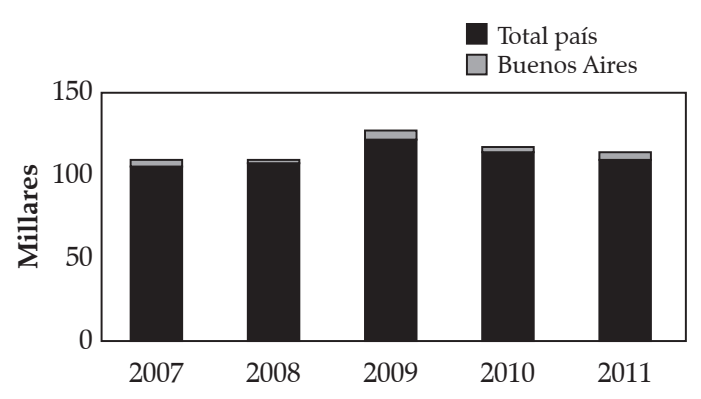

Fuente: Elaboración propia sobre la base de estadísticas del MCBA.

los comerciantes minoristas (verdulerías) y los supermercados, así como mercados concentradores de menor tamaño, o ubicados en localidades distantes (Instituto Nacional de Tecnología Agropecuaria, INTA, 2008).

La capacidad del área analizada de incidir en estos centros de venta mayorista varía según la fruta de que se trate. En cuanto al durazno remitido al Mercado Central, el análisis de la serie histórica 2000/1-2009/10 revela una tendencia a la disminución de la participación del área en el total ofertado (CMCBA-INTA, 2010). A pesar de ello, su peso en el volumen comercializado sigue siendo importante (del $31 \%$ anual en promedio para el período 2007-2012), y es significativo para los dos meses en que se concentra su producción (71\% y 58\% en noviembre y diciembre). En cambio en naranjas su participación tiende a ser decreciente y notablemente baja dentro del total - anualmente se ubica por debajo del $4 \%$, superando levemente este guarismo en los meses de julio, agosto y setiembre- (Figuras 3 y 4 ).

La fruta es remitida a los mercados concentradores en consignación, abonándose al operador del puesto (el puestero) una comisión por

influencia de este mercado como regulador de la cadena de comercialización. A ello se agrega que los demás mercados del Gran Buenos Aires carecen de los mismos controles de calidad y bromatológicos, y la aplicación de controles de precios en las frutas y hortalizas vendidas en el MCBA a partir de 2007. Todos estos aspectos favorecieron que los productores utilizaran mercados mayoristas alternativos (BOCCHICCHIO y CATTANEO, 2009). 
la venta del $12 \%$ del precio final. En los productores familiares entrevistados las transacciones se basan en relaciones interpersonales de larga data, en muchos casos construidas de generación en generación: "Gente que hace ya, yo no había nacido y mi papá ya les mandaba. Así que hace treinta y pico de años que están en el mercado" (caso 15). Algunos productores procuran agregar nuevos puesteros a los ya conocidos, en ocasiones contactados a través de los mismos fleteros que les transportan la fruta.

El aspecto fundamental que cimenta la continuidad de estas relaciones es la confianza en el cobro; con los "nuevos" puesteros se apela a recomendaciones de productores de otros rubros y transportistas de la fruta. Un productor relata al respecto: "El mismo camionero, te dice, 'tal persona vende bien', otro amigo puestero por ahí te dice 'mandale a fulano de tal, a ese no le mandés porque no te va a pagar" (caso 16). Sin embargo el precio constituye un aspecto problemático del vínculo: "Vos ves los números, ves las liquidaciones, increíble cómo uno te vende ponele 20, el otro te vendió 19, el otro 21 [...] Cuando la mercadería vale, te sacan. [...] Y cuando no vale te sacan uno o dos pesos" (caso 15). Por eso los productores procuran comparar los precios de diferentes puesteros; el contacto telefónico es cotidiano, y buscan tener presencia semanal en los mercados de manera de obtener otras referencias.

A pesar de la tensión involucrada en el tema del precio, cierto grado de reciprocidad está presente en estas relaciones mercantiles, en tanto un buen puestero cuida al productor que le provee de fruta (es decir, regula la oferta), mientras que éste trata de estar atento a sus requerimientos. También los fleteros procuran resguardar estos vínculos que presentan componentes recíprocos: el trabajo de uno está ligado al del otro, y cuando se corta la cadena todos se ven afectados en alguna medida.

Las redes que ligan a productores, transportistas y puesteros conforman un entramado denso que presenta continuidad en el tiempo. Vinculan puntos distantes en el espacio, y subyacen al aparente anonimato de mercados concentradores que, como en el caso del Mercado Central de Buenos Aires, tiene más de 700 puestos de venta. Por el contrario, conocer a las personas forma parte de las acciones que se realizan en este espacio social, siendo las interacciones concretas y personalizadas fundamentales para su dinámica (RADOMSKY y SCHNEIDER, 2007). Existen también redes que enlazan a algunos puesteros entre sí, traspasando lugares de mercado determinados, y a los puesteros con los pequeños comerciantes minoristas (VITERI, 2009).

\subsection{La venta a industria}

Este canal constituye un destino residual para la fruta del noreste bonaerense, puesto que sólo el 15\% de la producción de naranja del área sería procesada con este destino (INTA, 2008), menos aún en el caso del durazno. Es poco relevante para los productores familiares, ya que cuando venden la fruta "en planta" el descarte es canalizado a las industrias jugueras directamente por los empaques. Los precios pagados son bajos y los productores deben asumir los costos del traslado hasta las principales plantas procesadoras, que se encuentran en la provincia de Entre Ríos.

A pesar de que no constituye una buena opción de venta, se trata de un canal que algunos productores no desechan completamente, en tanto puede abrirles nuevas posibilidades. Es el caso de un productor con empaque, que está experimentando con la venta de cáscara de naranja para hacer fruta abrillantada: "Estamos entregando 800 kilos día por medio, la verdad que muy bien. Estamos viendo qué hacer con el tema de la pulpa [...] Ahora tenemos que mandar unas muestras a Buenos Aires, de 200 kilos, para ver si se puede hacer algo de jugo, algún exprimido o mermeladas" (caso 17).

En general los vínculos con las industrias procesadoras parecen ser de tipo ocasional, excepto en algunos pocos casos de productores familiares que suelen entregar parte de su producción a establecimientos elaboradores de dulces. Estos les plantean ciertos requerimientos 
en cuanto a las características que debe reunir la fruta, que contribuirían a reforzar el vínculo entre las partes. Como expresa un productor, "Me están comprando la naranja porque tiene un sabor dulce especial [...] Tiene que ser del campo al cajón y del cajón a la fábrica [...] Como usan la cáscara, no se puede echarle cera" (caso 15). Otro productor (caso 1) plantea que si bien no produce fruta orgánica, no puede emplear productos químicos para pulverizar: "la dulcera nos compra, pero es suficiente con que no tenga fosforados [...] nosotros curamos con aceite nada más".

\subsection{Los canales cortos de comercialización}

Una forma de comercialización de la fruta en el mercado interno menos visibilizada que las anteriores está representada por la venta de fruta en pequeña escala a través de canasteros (personas que compran algunos "bultos" de fruta para luego revenderlos), el reparto propio a comercios (verdulerías), y la venta directa en puestos de venta de productos regionales ubicados en la zona -ya sea propios o de terceros-. Una característica que define a estas alternativas, generalmente puestas en práctica por productores familiares, es el acortamiento de la cadena de comercialización. El precio obtenido por el productor es mayor, al tiempo que logra una disminución de costos al no acondicionar la fruta en empaques (ya que ésta no se lava o encera).

Este tipo de modalidad de venta directa ha sido en ciertas ocasiones iniciada por los productores como mecanismo transitorio ante coyunturas adversas: "Con un camioncito salíamos a vender a los pueblos [...] Íbamos a juntar la fruta en Entre Ríos, la traíamos y la preparábamos acá. [Fue] desde el año 95 hasta el 2000. Se nos heló lo nuestro acá y no teníamos fruta, y entonces íbamos allá a buscar naranjas y mandarinas" (caso 12). En otras situaciones el canal reviste continuidad, aunque el costo de transporte y las horas del día que insume el reparto a los comercios inciden en la organización del área de venta, que por lo general se reduce a San Pedro y partidos cercanos. Así un productor que mantiene actualmente esta modalidad, comenzó vendiendo a un empacador local parte de la producción en planta, sin embargo hoy trata de evitar los intermediarios, se hace cargo de la cosecha y vende en forma directa (a veces sin acondicionar la fruta) en su mismo campo y a verdulerías ubicadas en localidades cercanas: "porque a veces gana más el intermediario que el productor. Entonces sacando un eslaboncito, podemos seguir existiendo" (caso 10).

Algunos productores, en cambio, han optado por instalar puestos de venta o kioscos propios a la vera de la autopista 9 o sobre los accesos a la ciudad de San Pedro con el propósito de lograr una salida comercial para la producción de naranja, iniciando lo que con el tiempo se convertiría en una modalidad permanente de comercialización.

$\mathrm{Su}$ desarrollo se asocia con hogares multifuncionales caracterizados por el fuerte involucramiento del conjunto de los miembros en las tareas. Así en las familias que han encarado este camino las mujeres suelen estar a cargo de la atención de estos negocios y en algunos casos elaboran productos para la venta.

Se trata de una estrategia factible para quienes poseen explotaciones ubicadas sobre rutas de acceso aunque requiere de cierta inversión, entre ellas el aprovisionamiento de otros productos regionales con vistas a conformar una oferta diversificada que atraiga a los potenciales compradores. Por otro lado la venta directa es una opción funcional para la producción de naranja y no tanto para la de durazno, debido al carácter más perecedero de esta fruta.

No sólo los fruticultores familiares de la zona comenzaron con esta modalidad de venta, sino también viveristas (productores de plantas) y personas sin producción propia. En este último caso suelen comprar fruta a productores pequeños en función de la escala reducida que manejan: "Un fin de semana largo compran diez cajones de fruta. Y por ahí ese productor se la vende al kiosquito" (Entrevista a técnico privado).

Aunque también existen en la zona establecimientos de venta de productos regionales 
dirigidos a un público premium, la mayoría de estos puestos presenta una estructura sencilla. ${ }^{12}$ El crecimiento de esta modalidad está ligado a la redefinición de la inserción del medio rural local desde lo puramente agropecuario hacia una diversidad de usos, tanto productivos como no productivos. La ubicación de San Pedro sobre la ribera del río Paraná -con el atractivo que esto implica como paisaje y con la posibilidad de practicar la pesca y deportes náuticos- su cercanía a importantes centros urbanos de la Argentina como Buenos Aires y Rosario, son todos factores que han generado un aumento del turismo, particularmente durante los fines de semana.

A pesar de que la mayoría de los productores familiares carecen de puestos de venta propios, lo cierto es que la presencia de visitantes de fines de semana contribuye directa o indirectamente a dar salida a su producción. No obstante ello, la búsqueda de mayores interrelaciones entre las diferentes actividades es aún incipiente en la zona. ${ }^{13}$

\section{La diversificación de la comercialización como estrategia de los fruticultores familiares}

Retomando lo planteado en el punto dos de este trabajo, respecto a que los productores pueden construir sus formas de participación

12.Existen unos 55 puestos en funcionamiento en la zona, de los cuales la gran mayoría vende fruta. Las instalaciones suelen consistir en un barral donde se exhiben bolsas con frutas $u$ hortalizas (calabazas y batatas) y un espacio donde se ubican cajones con frutas y plantas. Además de ofrecer la mayoría de los productos frescos venden productos elaborados tales como dulces, licores, miel, embutidos y en algunos casos artesanías en mimbre e insumos para vivero (Agencia de Extensión Rural INTA San Pedro, comunicación personal, julio de 2012).

13.En el Plan estratégico del partido de San Pedro del año 2003 el desarrollo del turismo no aparece vinculado al objetivo de relanzamiento del sector frutihortícola. Tampoco aparece referencia al tema en el Plan de fortalecimiento de la cuenca frutícola del noreste bonaerense, iniciativa en la que convergen varias organizaciones públicas y privadas locales. Inclusive algunos actores vinculados a la fruticultura cuestionan lo que perciben como una priorización del turismo a costa de la actividad que los agrupa, o bien ponen en duda su capacidad de generar empleo para la población más vulnerable o menos calificada. en los mercados y eventualmente reorientar sus vínculos con ellos en un sentido que favorezca su reproducción social, analizamos en cada caso cómo los fruticultores familiares del área se insertaban concretamente en los distintos mercados. Así encontramos que despliegan una variedad de comportamientos para articularse con una diversidad de canales según el destino de la fruta: distribución local, extralocal, exportación e industria, ya que sólo un tercio emplea un único canal (Figura 5). Estos últimos son productores que venden "en planta" a un empacador o bien están integrados verticalmente y canalizan su fruta a través de mercados mayoristas.

Anteriormente era habitual que quienes accedían a este tipo de mercados vendieran exclusivamente en el Mercado Central de Buenos Aires a través de un único puestero. Por el contrario, en los últimos años han tenido que desarrollar comportamientos activos en pos de diversificar tanto mercados como puesteros a fin de poder colocar eficazmente su fruta. ${ }^{14}$

La diversificación productiva habitual en este tipo de productores, que incluye además del cítrico y el durazno, productos hortícolas como batata, zapallito y calabaza, favorece su acceso a los mercados concentradores y el logro de una mayor estabilidad en los vínculos. Además genera sinergias, en tanto la venta de hortalizas ayuda a ampliar la cartera de compradores de frutas y viceversa; se aprovechan los mismos contactos y se ofrecen a los mismos puesteros a los que se les remite mercadería durante todo el año (batata y cítricos en invierno y durazno en el verano). Como indica un productor: "Por el tema de la batata tuve que salir a buscar puestos que trabajaran más bolsas. [...] Me pude explayar y agrandar el tema de cítricos, trabajar más cantidad" (caso 17). Esto le permite prolongar la temporada de trabajo y por ende aumentar sus

\footnotetext{
14.Se diferencian así de los productores-empacadores locales que disponen de grandes volúmenes, y que al tener un costo operativo alto en materia de jornales prefieren trabajar con firmas de mayor tamaño, en tanto les permiten vender toda la mercadería en el mismo día aunque sea a precios más bajos.
} 
Figura 5. Canales de comercialización utilizados por los productores relevados

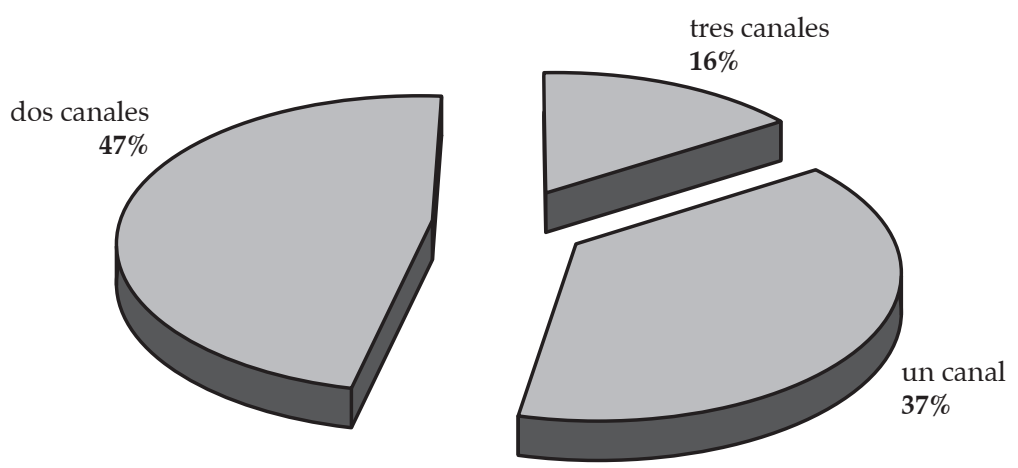

Fuente: Elaboración propia sobre información relevada. Entrevistas año 2011.

ingresos: Otro expresa: “Lo hago por necesidad de no poder pararme [...]. Ahora terminamos de trabajar el durazno y a los tres días empezamos a mandar batata porque si no, te comen los gatos" (caso 16).

No obstante el acceso a este canal de venta mayorista claramente está asociado al nivel de recursos de los productores. Así aquellos que emplean mano de obra familiar combinada con asalariados permanentes (un tipo social que en nuestro estudio denominamos familiarempresarial), son los que se contactan en mayor medida con mercados mayoristas y han conseguido avanzar en la integración vertical de actividades. Esto último implica un mayor acceso a capital fijo (un galpón de empaque y en algunos casos un camión para transportar la fruta) y cierto capital circulante para afrontar el costo de las etapas subsiguientes a la producción, hasta lograr armar el circuito. En contrapartida amplían su captación de ingresos de manera significativa con respecto a los productores no integrados verticalmente. ${ }^{15}$

15.Un estudio basado en datos de 2006 estimaba que en el caso de la naranja de San Pedro un 35\% de los costos directos de producción y comercialización correspondía a los gastos de flete, descarga y comisión de venta, mientras que un $21 \%$ al servicio de empaque. En el durazno los porcentajes eran del $27 \%$ y el $23 \%$ respectivamente. Si bien los costos del productor verticalmente integrado eran entre 3 y 4 veces mayores que los del productor que vendía "en planta" el margen bruto era entre 2 y 10 veces mayor, según el producto considerado (Pagliaricci et al., 2007).
Este grupo también compra fruta a otros productores si la demanda es sostenida, de manera de ampliar escala y reducir costos, y mantener a los puesteros abastecidos. De todos modos su integración vertical es parcial, en tanto no cuenta con puestos de comercialización propios o a cargo de miembros de la familia extensa en los mercados mayoristas, a diferencia de lo que ocurre con el mismo estrato de productores de la vecina provincia de Entre Ríos. ${ }^{16}$

Otro tipo de práctica presente en al menos un tercio de los fruticultores familiares entrevistados, pero fundamentalmente en los familiares puros (es decir, que se basan en el trabajo de sus familias y contratan asalariados para tareas puntuales) consiste en avanzar en la integración de actividades no ya a través del acceso a los mercados concentradores, sino a través del reparto en comercios minoristas de la zona y partidos cercanos o de la venta directa en puestos o negocios propios.

Sin embargo esta última modalidad de comercialización presenta limitaciones. Como señalamos previamente es más adecuada para la producción citrícola y no permite canalizar la totalidad de la misma, aunque se encuentre en retroceso. Un productor entrevistado es elocuente al respecto: "si vendería todo lo que

16.Esta sería una estrategia que se adecua más a las características de los productores entrerrianos debido al volumen que manejan y al carácter menos estacional de su oferta de fruta. 
tengo en el negocio estaría bien, chocho de la vida, ¿cierto?, pero vendo de a 50 cajones por semana" (caso 18). Por lo tanto estos productores necesitan conservar otras alternativas de venta. Así un productor familiar que vende sus naranjas ya cosechadas a un exportador retiene para sí el descarte que comercializa por su cuenta a las jugueras, a compradores sueltos, o a algunos kioscos de la zona. Otro vende sus naranjas a un empacador de mercado interno y sus mandarinas a través de un kiosco: “La iba a arrancar toda [...] este vecino que me hace labores tiene un kiosko en la ruta [...] Y me dijo [...] porqué no la dejás a la mandarina, porque ya hay poca mandarina para el mercado local [...] Y dejé alrededor de 200 plantas y la producción se la entrego toda a él. Yo la cosecho" (caso 4). Así, la estrategia de colocar parte de la producción en este tipo de canal que no demanda un volumen significativo y no involucra costos de procesamiento, le permite al productor sumar ingresos que se efectivizan de manera rápida, frente al pago de la fruta en un lapso más prolongado si la vende a los empaques. Complementa entonces ambas alternativas para lograr su reproducción.

\section{Conclusiones}

En una escala reducida, el espacio rural del noreste de la provincia de Buenos Aires es ilustrativo de ciertas transformaciones que se consolidan en la Argentina rural del nuevo milenio y afectan a los productores familiares en pequeña escala; entre ellos, la expansión de una agricultura extensiva de carácter empresarial orientada a los mercados mundiales en desmedro de otras actividades más intensivas en trabajo.

No obstante ello, la investigación realizada da cuenta de comportamientos particulares de los productores familiares que persisten en la actividad frutícola, a pesar del contexto más general que los condiciona. Estos tienen como eje común una creciente diversificación productiva, de mercados y de ingresos que se refuerza mutuamente. En base a lo presentado se podría argumentar que los fruticultores familiares que permanecen serían precisamente aquellos que han podido diversificar sus producciones $\mathrm{y}$ canales de comercialización.

El análisis del material cualitativo proveniente de las entrevistas revela el debilitamiento de los vínculos de los productores familiares no integrados con los productores-empacadores locales, dando cuenta de un proceso de desclusterización de la economía regional (PALACIOS y CRAVIOTTI, 2011). Todolo contrario a lo que sugieren algunos estudios de caso sobre encadenamientos productivos locales (DIRVEN, 2006), la situación de crisis de la fruticultura no ha ayudado a desencadenar acciones conjuntas en el terreno de las prácticas cotidianas, a excepción de algunos emprendimientos para el acceso en común a un galpón de empaque, pero éstos involucran a pocos productores, generalmente de mayor escala.

Frente a esta situación de debilitamiento de los vínculos entre productores y empacadores, las modalidades de venta directa a pequeños comercios o a través de kioscos a la vera de las rutas constituyen iniciativas que revisten un carácter estratégico. Es decir, lo que en primera instancia pareciera un comportamiento de tipo adaptativo o reactivo, supone de hecho la exploración de nuevas oportunidades, como las vinculadas al turismo de fines de semana.

La venta de fruta a los empaques -que podríamos caracterizar como el canal convencional de comercialización- y la venta directa no constituyen alternativas mutuamente excluyentes toda vez que los fruticultores las combinan, aún para el mismo producto, en proporciones que varían de temporada a temporada. Así, a diferencia de lo sostenido por enfoques que ven a los circuitos dominados por grandes empresas y a los mercados locales como circuitos separados y sostenidos por actores diferentes, encontramos un uso diferenciado y complementario de los mismos.

Aún así la gama de opciones disponibles en el terreno comercial está condicionada por la composición y variedad de capitales a los que acceden los productores y su posición en el 
espacio social (BOURDIEU, 1997), ya que la venta en mercados mayoristas es claramente mayor en los productores de tipo familiar-empresarial, que contratan mano de obra permanente como complemento a la aportada por sus hogares. Por otra parte las distintas posibilidades de comercialización repercuten sobre su capacidad y autonomía para lograr la reproducción social como productores.

Desde otro ángulo de análisis, y tal como lo revelan los aportes de la sociología económica, las transacciones encontradas se enraizan en vínculos personalizados, que si bien no están exentos de tensiones centradas principalmente en las formas de determinación de los precios, son probados y reconstruidos de manera continua. En consecuencia los canales de venta de estos agentes pueden ser vistos como configuraciones de redes diversas, que involucran relaciones personales y concretas con componentes múltiples, más que como intercambios puramente mercantiles.

Por otra parte y ya desde una visión más general, los resultados alcanzados en este trabajo aportan en el sentido de la importancia de profundizar en el conocimiento del carácter de las estrategias adaptativas y resistenciales puestas en juego en situaciones de retracción productiva. Además permiten efectuar una lectura que trasciende el caso en sí, en cuanto al acceso a recursos como condicionantes de la inserción en los mercados, y a la visualización de éstos como ámbito de interacción social donde se construyen nuevos vínculos y se modifican los anteriores.

\section{Bibliografía}

BIENABE, E. y VERMEULEN H. South Africa. New trends in supermarket procurement systems: the case of local procurement schemes from small-scale farmers by rural-based retail chain stores, Regoverning Markets Innovative Practice Series, Londres: IIED, 2008.

BOCCHICCHIO, A.yCATTANEO,C. “Comercialización, regulaciones y mercados frutihortícolas en el Área Metropolitana de Buenos Aires", en BENENCIA, R., QUARANTA G. y SOUZA CASADINHO, J., Cinturón hortícola de la ciudad de Buenos Aires: Cambios sociales y productivos, Buenos Aires, CICCUS, p. 155-194, 2009.
BOSELIE; D. y VAN der KOP P., Institutional and organisational changes in agri-food systems in developing and transitional countries: identifying opportunities for small holders, Regoverning Markets Issues Paper 2, Londres: IIED, 2005.

GRIFFIN, M. y FONGILLO, E. "Experiences and perspectives of farmers from Upstate New York farmers' markets", Agricultural and Human Values n. 20, p. 189-203, 2003.

BOURDIEU, P. "Le champ économique", Actes de la recherche en sciences sociales, v. 119, p. 48-66, 1997.

CONFERENCE ISSUES PAPER no. 4, "Farmer innovation. Linking with modern agrifood markets", International Conference, Beijing, 2008.

CONTERATO, M., NIEDERLE, P., RADOMSKY, G. y S. SCHNEIDER, "Mercantilizaçao e mercados: a construçao da diversidade da agricultura na ruralidade contemporánea", en SCHNEIDER S. Y GAZOLLA. M. Os atores do desenvolvimento rural. Porto Alegre: Editora da UFRGS, p. 67-89, 2011.

CRAVIOTTI, C. y PALACIOS, P., "Estrategias de productores familiares en contextos socio-productivos adversos: La fruticultura familiar en el noreste de la provincia de Buenos Aires", Trabajo y Sociedad, v. 17, p. 259-279, 2013.

CORPORACIÓN MERCADO CENTRAL DE BUENOS AIRES-INSTITUTO NACIONAL DE TECNOLOGÍA AGROPECUARIA (CMCBA-INTA), Boletín electrónico de frutas de carozo, n. 13, 2010.

CRAVIOTTI, C., PALACIOS, P. y SOLENO WILCHES, R. "Reestructuración productiva e inserción en los mercados. La pequeña y mediana citricultura de la subregión del Río Uruguay" en CRAVIOTTI, C. (coord.), Tramas productivas y agentes sociales en la fruticultura globalizada, Buenos Aires, Miño y Dávila, p. 25-54, 2012.

DIRVEN, M. "Acción conjunta en los clusters: entre la teoría y los estudios de caso", Seminario Internacional "Territorios rurales en movimiento", Santiago de Chile, 23 al 26 de abril de 2006.

DUBUISSON-QUELLIER, S. y LE VELLY, R. "Les circuits courts entre alternative et hybridation", en MARÉCHAL (dir.), Les circuits courts alimentaires. Bien manger dans les territoires, Dijon: Educagri., collection Références, p. 105-112, 2008.

GRANOVETTER, M., "Economic action and social structure: The problem of embeddedness", American Journal of Sociology, v. 91, p. 481-510, 1985. 
GUTMAN; G., Agricultura de contrato de pequeños productores agropecuarios con agroindustrias $y / o$ agrocomercios en Argentina. Experiencias, lecciones, lineamientos de políticas. Documento efectuado en el marco de la preparación de la estrategia nacional de Desarrollo Rural para la Argentina, Buenos Aires: RIMISP, 2005.

HAZELL, P. POULTON, C., WIGGINS, S. y DORWARD, A. "The Future of Small Farms: Trajectories and Policy Priorities", World Development, v. 20, n. 10, p. 1453-1526, 2010.

MARKELOVA, H., MEINZEN-DICK, R., HELLIN, J. y DOHRN, S. "Collective action for smallholder market access", Food Policy, n. 34, p. 1-7, 2009.

INSTITUTO NACIONAL DE TECNOLOGÍA AGROPECUARIA (INTA), Diagnóstico Plan Tecnológico Regional 2009-2011 Centro Regional Buenos Aires Norte: Cadenas Frutícolas, INTA, Centro Regional Buenos Aires Norte, Buenos Aires, 2008.

INSTITUTO NACIONAL DE TECNOLOGÍA AGROPECUARIA (INTA), Boletín Electrónico de frutas de carozo núm. 13, Corporación del Mercado Central de Buenos Aires, Buenos Aires, marzo de 2010.

LONG. N. y VAN DER PLOEG. J. D., "Heterogeneity, actor and structure: towards a reconstitution of the concept of structure. En BOOTH, D. (ed.), Rethinking social development: theory, research and practice. Harlow: Longman, 1004.

MARSDEN, T., BANKS, J. y BRISTOW, G. "Food supply chain approaches: exploring their role in rural development", Sociologia Ruralis, v. 40, p. 424-437, 2000.

PALACIOS, P. y CRAVIOTTI, C. "Una producción en retracción o en (re)definición?: la citricultura en el noreste de la provincia de Buenos Aires, Argentina", XXXII Congreso Nacional y XVII Internacional de Geografía, Sociedad Chilena de Ciencias Geográficas, Valparaíso, 22 al 25 de noviembre de 2011.

PAGLIARICCI, L., ARROYO, L. y VALENTINI, G. "Evaluación económica de distintas modalidades de comercialización de duraznos y naranjas para consumo interno en fresco en el norte de la provincia de Buenos Aires", Buenos Aires, 2007 (consultado el 18 de julio de
2012), disponible en: <http://inta.gob.ar/documentos/ evaluacion-economica-de-distintas-modalidadesde-comercializacion-de-duraznos-y-naranjas-paraconsumo-interno-en-fresco-en-el-norte-de-la-provincia-de-buenos-aires $>$.

PAGLIARICCI, L. "Cambios estructurales en la fruticultura de San Pedro", Informe marzo 2011, Proyecto regional de desarrollo territorial, INTA, Buenos Aires, p. 13-15, 2011.

RADOMSKY, G. y SCHNEIDER, S. "Nas teias da economia: O papel das redes sociais e da reciprocidade nos procesos de desenvolvimento", Sociedade e Estado, v. 22, n. 2, p. 249-284, 2007.

REARDON, T., BARRETT, C., BERDEGUE J. y SWINNEN, J. "Agri-food industry transformation and small farmers in developing countries", World Development, v. 37, n. 11, p. 1717-1727, 2009.

RENTING,H.,MARDEN, T.yBANKS,J.“Understanding alternative food networks: exploring the role of short food supply chains in rural development", Environment and Planning A, v. 35, p. 393-411, 2003.

SAGE, C. "Social embeddedness and relations of regard: Alternative 'good food' networks in south-west England", Journal of Rural Studies, v. 19, p. 47-60, 2003.

VITERI, M. L., “The Buenos Aires Central Wholesale Market (BACWN): A Case of Multiple Power", International Journal of Sociology of Agriculture and Food, v. 16, n. 2, p. 54-69, 2009.

ZELIZER, V., "Past and futures of economic sociology", American Behavioral Scientist, n. 50, p. 1056-69, 2007.

\subsection{Otras fuentes}

Corporación del Mercado Central de Buenos Aires (CMCBA): Estadísticas, varios años.

Federación del Citrus, La actividad citrícola argentina, varios años.

Servicio Nacional de Calidad y Sanidad Agroalimentaria -SENASA- Estadísticas de frutas frescas. Importaciones y exportaciones, varios años. 